\title{
High prevalence of dyslipidemia among primary care patients with hypertension and diabetes in Jamaica
}

Michelle A. Harris ${ }^{1}$, Trevor S. Ferguson², Michael S. Boyne², J. Peter Figueroa ${ }^{1}$

${ }^{1}$ Department of Community Health and Psychiatry, Faculty of Medical Sciences, University of the West Indies, Mona, Jamaica

${ }^{2}$ Caribbean Institute for Health Research, University of the West Indies, Mona, Jamaica

Submitted: 4 August 2017

Accepted: 22 August 2017

Arch Med Sci Atheroscler Dis 2017; 2: e61-e67

DOI: https://doi.org/10.5114/amsad.2017.70596

Copyright $\odot 2017$ Termedia \& Banach

\section{Abstract}

Introduction: The aim of the study was to determine the prevalence of dyslipidemia among primary care patients with hypertension and diabetes in Jamaica and the proportion of patients who achieve recommended targets. Material and methods: An audit of 500 dockets of adult patients with chronic disease attending public primary care clinics in Jamaica was conducted between October and December 2013. Data were collected on patient characteristics including medical history, medications, anthropometry, and lipid profiles (since January 1, 2011). Lipid targets were based on the Ministry of Health 2007 management guidelines. Stepwise multivariable logistic regression analysis was performed to determine the predictors of achieving lipid targets.

Results: Four hundred and thirty-seven patient records had a lipid profile done and $90 \%$ of these had at least one abnormal lipid value. $15.3 \%$ of the patients achieved the low density lipoprotein cholesterol (LDL-C) target, $63.2 \%$ high density lipoprotein cholesterol (HDL-C), $85.1 \%$ triglycerides and $57.4 \%$ the total cholesterol target. Statins were prescribed for $49 \%$ and these patients were less likely to achieve LDL-C (OR $=0.57 ; 95 \% \mathrm{Cl}: 0.33-$ $0.97 ; p=0.04)$ or total cholesterol $(\mathrm{OR}=0.21 ; 95 \% \mathrm{Cl}: 0.13-0.33 ; p<0.001)$ targets. Patients over 80 years were more likely to achieve the LDL-C target $(\mathrm{OR}=3.21 ; 95 \% \mathrm{Cl}: 1.64-6.28 ; p=0.002)$ than those less than 50 years old. More men than women achieved total cholesterol targets $(\mathrm{OR}=2.2 ; 95 \% \mathrm{Cl}$ : $1.4-3.6 ; p=0.001$ ).

Conclusions: Dyslipidemia is widespread among primary care patients with hypertension and diabetes. The proportion of patients who achieve the respective lipid targets must be documented and routinely monitored and appropriate medication and lifestyle changes implemented to improve this.

Key words: hypertension, dyslipidemia, Jamaica, primary care.

\author{
Corresponding author: \\ Michelle A. Harris ${ }^{1}$ \\ Faculty of \\ Medical Sciences \\ University of \\ the West Indies \\ Mona, Kingston 7 \\ Jamaica \\ E-mail: michelle.harris06@ \\ gmail.com
}

\section{Introduction}

Dyslipidemia is a major risk factor for cardiovascular disease and is estimated to cause 2.6 million deaths and 29.7 million disability-adjusted life years globally [1]. Its prevalence varies widely across populations. The global prevalence of raised total cholesterol in 2008 was $9.7 \%$ among adults, with $8.5 \%$ for males and $10.7 \%$ for females [1, 2]. In the US, $26 \%$ of adults over 20 years had hypercholesterolemia [3] and $45 \%$ of the population 18 to 79 years old in Canada had dyslipidemia [4]. 
In the Caribbean, dyslipidemia is also an important health problem. The Jamaica Health and Lifestyle survey (JHLSII) of 2008 found a prevalence of high total cholesterol of $11.7 \%$ among individuals aged 15-74 years [5]. The prevalence was greater among females and increased with age; from $1 \%$ among males aged $15-24$ years to $17.7 \%$ among those aged $65-74$ years. The prevalence ranged from $7 \%$ among females aged 15-24 years to $32 \%$ among those aged $55-64$ years [5]. Among patients with metabolic syndrome from the Spanish Town Cohort Study, low high density lipoprotein cholesterol (HDL-C) occurred in 58.6\% of women and $24.8 \%$ of men and elevated triglycerides among $11 \%$ of men and $8 \%$ of women [6]. The prevalence of high cholesterol was $21 \%$ in Barbados [7] and 7.9\% in Trinidad and Tobago [8].

Dyslipidemia is a state of abnormal levels of lipids in plasma [9] and therefore encompasses a wide spectrum of disorders. Primary dyslipidemias caused by genetic disorders of lipoprotein metabolism account for $20 \%$ of all dyslipidemias globally [10]. Secondary dyslipidemias are alterations in lipoprotein metabolism that complicate or occur in the presence of other medical conditions [11]. A common form of mixed dyslipidemia is seen in patients with type 2 diabetes mellitus (T2DM), and metabolic syndrome and is characterized by a high number of small dense LDL particles, low $\mathrm{HDL}-\mathrm{C}$ and high levels of triglycerides; this is also referred to as atherogenic dyslipidemia [10, 12].

Low density lipoprotein cholesterol (LDL-C) has long been the primary target for lipid control with statins as the mainstay of lipid treatment [13]. There is however growing evidence that there is residual cardiovascular disease (CVD) risk even after the LDL-C goal is achieved [13] and this is thought to be a result of sub-optimal non-HDL-C levels [14]. The non-HDL-C level has been recommended by some as a secondary target in the management of dyslipidemia especially among patients with elevated triglycerides. Atherosclerotic diseases, i.e. stroke and ischemic heart disease, are the leading causes of death in the Caribbean [15]. However, there is a dearth of data on the disease prevalence and the achievement of lipid targets among patients with hypertension and diabetes who are at increased risk of atherosclerotic disease. The objective of this study was to describe the prevalence of dyslipidemia among patients with hypertension and diabetes who attend primary care clinics in Jamaica and the proportion who achieve lipid targets.

\section{Material and methods}

\section{Study design}

This study was part of a randomized controlled trial (RCT) of an intervention to improve the man- agement of dyslipidemia among patients attending primary care clinics in the South-East region of Jamaica. In the RCT, a baseline audit was conducted on 500 records from six randomly selected health centers. The records were included if patients were 18 years old and over and had attended the chronic disease clinic for at least 18 months. The RCT involved a baseline audit, an intervention that lasted for 12 months, and a re-audit at three of the six health centers. The intervention included feedback from the baseline audit, introductory training in motivational interviewing for the clinicians, use of a reminder stamp detailing process of care measures in the patient records and the distribution of patient education cards after the routine educational sessions. At the re-audit, patient outcomes and process of care measures implemented at the intervention and control sites were compared. The methodology of the RCT is reported in greater detail elsewhere [16]. The data reported in this paper are taken from the second audit done in 2013. The Ethical Review boards of the University of the West Indies and the South East Regional Health Authority granted ethical approval.

\section{Measurements}

The audit criteria were derived from the Ministry of Health 2007 guidelines for the management of hypertension and diabetes [17]. The targets for the various lipid fractions were: total cholesterol $<5.2 \mathrm{mmol} / \mathrm{l}$; LDL-C < $2.6 \mathrm{mmol} / \mathrm{l}$; HDL-C > 1.1 $\mathrm{mmol} / \mathrm{l}$ in men and $\mathrm{HDL}-\mathrm{C}>1.3 \mathrm{mmol} / \mathrm{l}$ in women and triglycerides $<1.7 \mathrm{mmol} / \mathrm{l}$. Included in the analysis were 437 lipid profiles that were reported on between January 2011 and December 2013.

\section{Statistical analysis}

We reported patient characteristics by sex, mean lipid values and proportions of patients who achieved the lipid targets. Differences in proportions were compared using the $\chi^{2}$ test, and the $t$-test was used to assess for the differences in means. Stepwise multivariable logistic regression analysis was conducted to determine the predic tors of achieving lipid targets. All analyses were performed using Stata 13 (Stata Corp, College Station Texas).

\section{Results}

Of the 500 patient dockets that were reviewed, 437 patients had at least one lipid profile done since January 2011 and the most recent lipid test for each patient was included in the analysis. Thirty-five percent of the sample were men and they were marginally older than the women (mean age 66.5 years vs. 62.4 years). Most patients (93.4\%) 
Table I. Summary of clinical characteristics by sex in 437 adult patients with chronic disease attending public primary care clinics in Jamaica

\begin{tabular}{|c|c|c|c|c|c|c|}
\hline \multirow[t]{2}{*}{ Characteristic } & \multicolumn{2}{|c|}{ Men $(n=153)$} & \multicolumn{2}{|c|}{ Women $(n=284)$} & \multicolumn{2}{|c|}{ Total $(N=437)$} \\
\hline & Mean & SD & Mean & SD & Mean & SD \\
\hline \multirow[t]{2}{*}{ Age [years] ${ }^{* *}$} & 66.5 & 11.2 & 62.4 & 13.5 & 63.8 & 12.9 \\
\hline & $N$ & $\%$ & $N$ & $\%$ & $N$ & $\%$ \\
\hline \multicolumn{7}{|l|}{ Medical history: } \\
\hline Hypertension & 139 & 90.9 & 269 & 94.7 & 408 & 93.4 \\
\hline Diabetes mellitus & 77 & 50.3 & 134 & 47.2 & 211 & 48.0 \\
\hline Heart disease & 21 & 13.7 & 28 & 9.9 & 49 & 11.2 \\
\hline Stroke & 11 & 7.2 & 13 & 4.9 & 24 & 5.5 \\
\hline Peripheral artery disease & 30 & 19.6 & 64 & 22.5 & 94 & 21.5 \\
\hline \multicolumn{7}{|l|}{ Prescribed medications: } \\
\hline Antihypertensive drugs & 138 & 90.8 & 264 & 93.3 & 402 & 92.4 \\
\hline Insulin & 20 & 13.1 & 29 & 10.3 & 49 & 11.2 \\
\hline Oral hypoglycemic drugs & 73 & 47.7 & 125 & 44.4 & 198 & 45.3 \\
\hline Statins $^{* * *}$ & 62 & 41.3 & 169 & 59.5 & 231 & 53.6 \\
\hline Aspirin & 89 & 58.6 & 169 & 59.5 & 258 & 59.0 \\
\hline \multicolumn{7}{|l|}{ Other characteristics: } \\
\hline Current smoker & 14 & 9.2 & 8 & 2.8 & 22 & 5.0 \\
\hline Alcohol use & 15 & 9.8 & 7 & 2.5 & 22 & 5.0 \\
\hline
\end{tabular}

were diagnosed with hypertension while $48 \%$ had diabetes. A history of heart disease was recorded among $11.2 \%$ of the patients and $21.5 \%$ had a history of peripheral vascular disease.

Statins were prescribed for $53.6 \%$ of the patients and more often among the women. Insulin was prescribed for $11.2 \%$ of patients and $45.3 \%$ were prescribed an oral hypo-glycaemic medication. Smoking and alcohol use was documented for very few of the patients and was reported more among the men than the women (Table I).

Of the 437 lipid profiles reviewed, 394 or $90 \%$ had at least one abnormal lipid value. The mean concentrations of the various lipid fractions and the percentage of the patients who achieved the targets are presented in Figure 1. LDL-C was within the target for $15.3 \%$ of the patients, HDL-C for $63.2 \%$, triglycerides for $85.1 \%$ and total cholesterol for $57.4 \%$.

Tables II and III present the mean lipid concentrations and the proportion of patients who were within the lipid targets by sex and by statin use. More men than women achieved each of the lipid targets and men were two times as likely to be within the target for total cholesterol $(O R=2.04$; 95\% Cl: 1.29-3.22; $p<0.01$ ) (Table II). The mean LDL-C concentration was elevated while the mean
HDL-C and triglyceride concentrations were within the normal range. The mean total cholesterol was elevated among the women but was normal for the men.

Patients who were prescribed a statin were less likely to achieve the lipid targets, and the mean lipid values were higher than among those who were not prescribed medications. For example, patients prescribed statins were $79 \%$ less likely to achieve the total cholesterol target $(\mathrm{OR}=0.21$; 95\% Cl: $0.13-0.32 ; p<0.001)$ than those not on

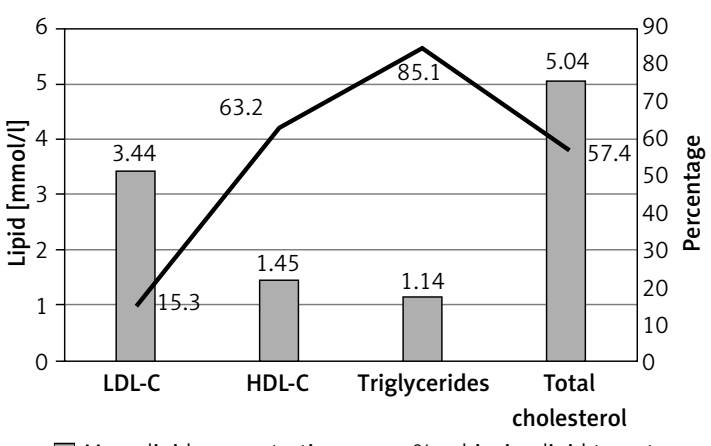

$\square$ Mean lipid concentrations $\quad-\%$ achieving lipid target Figure 1. Mean lipid concentrations and the percentage achieving the various lipid targets among 437 adult patients with hypertension and diabetes attending primary care clinics in Jamaica 
Table II. Mean lipid concentrations and lipid targets $(95 \% \mathrm{Cl})$ achieved by sex in 437 adult patients with hypertension and diabetes attending primary care clinics in Jamaica

\begin{tabular}{|c|c|c|c|c|c|}
\hline \multirow[t]{2}{*}{ Lipid fraction } & \multicolumn{2}{|c|}{ Mean lipid values [mmol/l] } & \multicolumn{2}{|c|}{ Lipid target achieved (\%) } & \multirow{2}{*}{$\begin{array}{l}\text { Odds }^{2} \text { of achiev- } \\
\text { ing target, men } \\
\text { vs. women }\end{array}$} \\
\hline & $\begin{array}{c}\text { Men } \\
(n=141)\end{array}$ & $\begin{array}{l}\text { Women } \\
(n=153)\end{array}$ & $\begin{array}{c}\text { Men } \\
(n=153)\end{array}$ & $\begin{array}{l}\text { Women } \\
(n=284)\end{array}$ & \\
\hline LDL-C & $\begin{array}{c}3.25 \\
(3.11,3.38)\end{array}$ & $\begin{array}{c}3.25 \\
(3.42,3.69)\end{array}$ & $\begin{array}{c}19.6 \\
(13.3,25.9)\end{array}$ & $\begin{array}{c}13.0 \\
(9.1,16.9)\end{array}$ & $\begin{array}{c}1.35 \\
(0.78,2.34)\end{array}$ \\
\hline $\mathrm{HDL}-\mathrm{C}$ & $\begin{array}{c}1.27 \\
(1.21,1.33)\end{array}$ & $\begin{array}{c}1.55 \\
(1.45,1.64)\end{array}$ & $\begin{array}{c}63.4 \\
(55.8,71.0) \\
\end{array}$ & $\begin{array}{c}63.0 \\
(57.4,68.6) \\
\end{array}$ & $\begin{array}{c}0.88 \\
(0.58,1.35)\end{array}$ \\
\hline Triglycerides & $\begin{array}{c}1.15 \\
(1.02,1.17)\end{array}$ & $\begin{array}{c}1.17 \\
(1.11,1.22)\end{array}$ & $\begin{array}{c}88.2 \\
(83.1,93.3)\end{array}$ & $\begin{array}{c}83.5 \\
(79.1,87.8)\end{array}$ & $\begin{array}{c}1.18 \\
(0.64,2.18)\end{array}$ \\
\hline Total cholesterol & $\begin{array}{c}4.77 \\
(4.56,4.83)\end{array}$ & $\begin{array}{c}5.22 \\
(5.10,5.33)\end{array}$ & $\begin{array}{c}71.9 \\
(64.8,79.0)\end{array}$ & $\begin{array}{c}49.6^{\star * \star 1} \\
(43.8,55.5)\end{array}$ & $\begin{array}{c}2.04^{\star \star} \\
(1.29,3.22)\end{array}$ \\
\hline
\end{tabular}

${ }^{\star} P<0.05,{ }^{* *} p<0.01,{ }^{* *} p<0.001 ;{ }^{1}$ comparing target achieved by men vs. women; ${ }^{2}$ adjusted for age and statin use.

Table III. Mean lipid concentrations and lipid targets $(95 \% \mathrm{Cl})$ achieved by statin use in 437 adult patients with hypertension and diabetes that attend primary care clinics in Jamaica

\begin{tabular}{|c|c|c|c|c|c|}
\hline \multirow{2}{*}{$\begin{array}{l}\text { Lipid } \\
\text { fraction }\end{array}$} & \multicolumn{2}{|c|}{ Mean concentration [mmol/l] } & \multicolumn{2}{|c|}{$\%$ achieved lipid target } & \multirow{2}{*}{$\begin{array}{l}\text { Prevalence ratio of } \\
\text { target achieved, statin } \\
\text { user vs. non-statin user }\end{array}$} \\
\hline & Statin user & No statin use & Statin user & No statin use & \\
\hline LDL-C & $\begin{array}{c}3.73 \\
(3.59,3.88)\end{array}$ & $\begin{array}{c}3.11 \\
(3.00,3.23)\end{array}$ & $\begin{array}{c}12.1 \\
(7.9,16.3)\end{array}$ & $\begin{array}{c}19.0 \\
(13.6,24.4)\end{array}$ & 0.63 \\
\hline HDL-C & $\begin{array}{c}1.48 \\
(1.38,1.59)\end{array}$ & $\begin{array}{c}1.42 \\
(1.33,1.50)\end{array}$ & $\begin{array}{c}61.0 \\
(54.8,67.3)\end{array}$ & $\begin{array}{c}66.0 \\
(59.4,72.6)\end{array}$ & 0.92 \\
\hline Triglycerides & $\begin{array}{c}1.28 \\
(1.21,1.35)\end{array}$ & $\begin{array}{c}0.99 \\
(0.93,1.04)\end{array}$ & $\begin{array}{c}77.9 \\
(72.6,83.3)\end{array}$ & $\begin{array}{c}93.5^{* * * 1} \\
(90.1,96.9)\end{array}$ & 0.83 \\
\hline $\begin{array}{l}\text { Total } \\
\text { cholesterol }\end{array}$ & $\begin{array}{c}5.39 \\
(5.26,5.52)\end{array}$ & $\begin{array}{c}4.64 \\
(4.54,4.74)\end{array}$ & $\begin{array}{c}39.8 \\
(33.5,46.1)\end{array}$ & $\begin{array}{c}77.5^{* * * 1} \\
(71.7,83.3)\end{array}$ & 0.51 \\
\hline
\end{tabular}

${ }^{\star} P<0.05 ;{ }^{* \star *} p<0.001 ;{ }^{1}$ comparing target achieved by statin user vs non-statin user; ${ }^{2}$ adjusted for age and sex.

a statin, and only $39 \%$ of them were at goal compared with $77.5 \%$ of those not on a statin. Significantly more of the patients over 80 years old (31.4\%) achieved the LDL-C goal, as did those aged $70-79$ years $(10.5 \%)$, when compared with the total sample (15.3\%) of patients. While there was no age difference among those who achieved HDL-C and triglyceride targets, more of the patients in the groups older than 80 years and younger than 50 years achieved the LDL-C and total cholesterol goals compared to patients in other age groups (Figure 2). The mean LDL-C

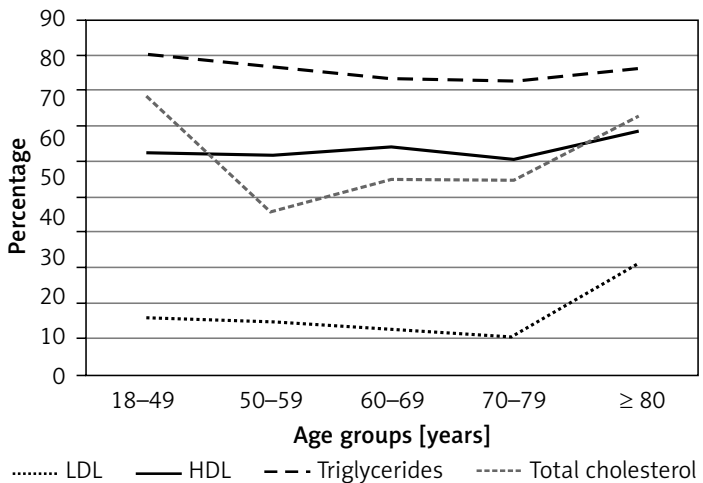

Figure 2. Lipid targets achieved by age groups in 437 adult patients with hypertension and diabetes attending primary care clinics in Jamaica and total cholesterol values were within the normal range for the patients less than 50 and over 80 years of age.

Multiple logistic regression showed that achieving the LDL-C target was not affected by sex or being diagnosed with T2DM. However, those who were 80 years old or older were 3.2 times as likely to achieve the LDL-C target when compared with those less than 50 years of age $(\mathrm{OR}=3.21 ; 95 \% \mathrm{Cl}$ : 1.64-6.28; $p=0.001$ ), and those prescribed statin medication were less likely to be within the target $(\mathrm{OR}=0.57,95 \% \mathrm{Cl}: 0.33-0.97 ; p=0.04)$. Age, sex or a diagnosis of T2DM did not affect achieving the triglycerides or HDL-C targets. However, those who were prescribed a statin were $75 \%$ less likely to achieve the triglyceride goal $(\mathrm{OR}=0.25,95 \% \mathrm{Cl}$ : $0.13-0.47 ; p<0.001$ ).

Oral anti-lipid medications were prescribed for 243 of the patients and 131 of them were diagnosed with diabetes. Of those offered medication, 212 or $87 \%$ were prescribed simvastatin either alone or in combination with niacin or with ezetimibe. Of those prescribed simvastatin alone, $35 \%$ were prescribed $10 \mathrm{mg}, 51 \%$ were prescribed $20 \mathrm{mg}$ and $9 \%$ were prescribed $40 \mathrm{mg}$. Atorvastatin was the second most common statin prescribed and was given to 23 patients. Of these, 
Table IV. Lipid-lowering medications prescribed and the doses for patients with hypertension and diabetes attending primary care clinics in Jamaica

\begin{tabular}{|c|c|c|c|c|c|}
\hline \multirow{2}{*}{$\begin{array}{l}\text { Anti-lipid } \\
\text { medication }\end{array}$} & \multirow[t]{2}{*}{$N(\%)$} & \multicolumn{4}{|c|}{ Dosage } \\
\hline & & $10 \mathrm{mg}$ & $20 \mathrm{mg}$ & $40 \mathrm{mg}$ & $60 \mathrm{mg}$ \\
\hline Simvastatin & $180(74.1)$ & 65 (36\%) & $92(51 \%)$ & $16(9 \%)$ & $1(1 \%)$ \\
\hline $\begin{array}{l}\text { Simvastatin } \\
\text { and niacin }\end{array}$ & $28(11.5)$ & 4 (14\%) & $16(57 \%)$ & $8(29 \%)$ & 0 \\
\hline $\begin{array}{l}\text { Simvastatin } \\
\text { and ezetimibe }\end{array}$ & $4(1.6)$ & $1(25 \%)$ & $1(25 \%)$ & $1(25 \%)$ & $1(25 \%)$ \\
\hline Atorvastatin & $23(9.5)$ & $8(35 \%)$ & $13(57 \%)$ & $2(9 \%)$ & 0 \\
\hline Rosuvastatin & $1(0.4)$ & $1(100 \%)$ & 0 & 0 & 0 \\
\hline Pravastatin & $1(0.4)$ & 0 & 0 & $1(100 \%)$ & 0 \\
\hline Niacin & $1(0.4)$ & - & - & - & - \\
\hline Not documented & $5(2.1)$ & - & - & - & - \\
\hline
\end{tabular}

8 were prescribed $10 \mathrm{mg}, 13$ were prescribed $20 \mathrm{mg}$, and 2 were prescribed $40 \mathrm{mg}$ (Table IV).

\section{Discussion}

There is a high prevalence of abnormal lipid values among patients with hypertension and diabetes mellitus who attend public primary care clinics. While a diagnosis of hypertension or diabetes was routinely recorded in the patient charts, a diagnosis of high cholesterol or dyslipidemia was very rarely documented in patient charts. Given that statins are commonly recommended as primary prevention for cardiovascular disease among patients with diabetes mellitus [18], the researchers did not automatically designate each patient who was prescribed a statin as a patient with dyslipidemia. The clinicians must be encouraged to make this specific diagnosis based on their assessment of the patients. The recognition of dyslipidemia and its prevalence among primary care patients with hypertension and diabetes is the first step towards addressing this largely modifiable cardiovascular disease risk factor.

LDL-C was the lipid fraction that was least likely to be at goal among the patients in this study. This differs from what was reported from Canada [19], the UK [20] and the Middle East [21], where more patients were at goal for LDL-C than for the other lipid fractions. Given that LDL-C dyslipidemia was the predominant form of dyslipidemia observed in this study and that the surveys in Jamaica most often reported on total cholesterol [5], it is likely that the extent of the dyslipidemia problem in Jamaica has been underestimated. An earlier population-based cross-sectional survey among Jamaican adult patients with hypertension and diabetes had mean LDL-C values above target while the other lipid fraction were within the normal range [22]. It would be useful to ex- plore further the type of dyslipidemia that affects patients in Jamaica.

Patients who were prescribed lipid-lowering medications were less likely to achieve their lipid goals. This is not surprising as these were most likely the patients with established dyslipidemia. The lack of control of their condition could be because of non-adherence to the medication or because the prescribed medication was not effective in helping these patients to achieve their lipid targets. While all patients included in the study had been attending their primary care clinic for at least 18 months, the time since they were prescribed lipid-lowering medication was not captured in the data. It is quite possible that patients who were prescribed statins had higher lipid values initially, and what was being observed reflected an improvement in their lipid concentrations. Lastly, the poor control observed could be a result of the patients not being aware of the targets that they should be trying to achieve or the physicians not taking the time to monitor the levels of control among their patients.

Most of the patients were prescribed $10 \mathrm{mg}$ or $20 \mathrm{mg}$ of simvastatin. Although the lipid goals were not achieved, very few patients were prescribed the maximum dose of $40 \mathrm{mg}$. This underscores the need to set clear treatment goals and for providers to treat to goal. Once medication adherence is confirmed, then the dose should be increased or a change made to one of the newer statins that may be more effective. It was reported previously that access to the newer classes of hypertensive medications may have contributed to improved hypertension control among this cohort of patients [23]. On the other hand, the failure to intensify treatment among a visit-adherent cohort of patients with diabetes was shown to be associated with their sub-optimal control [18]. As poor provider/patient relationships, poor communica- 
tion skills and patient misinformation can negatively impact patient adherence [24], there needs to be ongoing training and monitoring of these aspects of patient care.

This study did not assess patient adherence, and it would be useful to explore patient adherence as well as their knowledge and perceptions of lipid-lowering medications in a follow-up study. Guidelines for the care and management of select conditions are usually developed and disseminated among health care providers in an effort to ensure that uniform standards of practice are adopted across various settings. While the Caribbean Cardiology Society developed guidelines for the management of dyslipidemia in 2008, these have not been adapted for use among primary care providers in the public sector. It is not enough to have guidelines for the management of chronic illnesses; they must be disseminated and the providers trained in their use [25].

Our study showed that men were more likely than women to achieve the lipid targets, and this was similar to the results from the Jamaica Health and Lifestyle Survey [5] and a population-based survey among the elderly [26]. This can possibly be attributed to the higher levels of overweight and obesity and lower levels of physical activity among women when compared with men.

The fact that the lipid profile results that were already in the patient charts were used to assess lipid control rather than carrying out new tests is a limitation of the study. No data on adherence to medications were collected to determine the extent to which this contributed to the poor lipid goal attainment that was observed. There was also no clear indication of which patients were diagnosed with dyslipidemia nor the time since such a diagnosis was made. The absence of recorded heights did not allow us to assess the effect of BMI on lipid control.

In coclusion, dyslipidemia is widespread among patients with chronic illnesses who attend public primary care clinics. Too few of the patients are achieving the lipid targets even though men are more likely than women to achieve these targets. We recommend that the proportion of patients who attain the respective lipid targets should be routinely monitored. Lipid guidelines must be updated and disseminated to primary care providers, and they should be equipped with strategies to improve their communication skills and provider/ patient relationships in order to improve patient adherence. The most effective lipid-lowering medications should be made available to the patients seeking care in the primary care setting.

\section{Conflict of interest}

The authors declare no conflict of interest.

\section{References}

1. World Health Organization. Global Atlas on Cardiovascular diseases prevention and control. Geneva 2011.

2. World Health Organization. Global status report on non-communicable diseases 2010. Geneva 2010.

3. Go AS, Mozaffarian D, Roger VL, et al. Heart and stroke statistics-2013 update a report of the American Health Association. Circulation 2013; 127: e6-e245. doi: 10.1161/ CIR.0b013e31828134ad.

4. Joffres M, Shields M, Tremblay MS, Conner Gorber S. Dyslipidemia prevalence, treatment control and awareness in the Canadian Health Measures survey. Can J Public Health 2013; 104: 252-7.

5. Wilks R, Younger N, Tulloch-Reid M, McFarlane S, Francis D, Group JHLs. Jamaica Health and Lifestyle Survey 2007-8. http://caribbean.scielo.org/scielo.php?script=sci_arttext\&pid=S0043-31442012000400015\&lng=en\&nrm=iso: Tropical Medicine Research Institute, Epidemiology Research Unit; 2008 Contract No.: Report No.: ISO 9001:2000. Cert No.: 4533//04.

6. Ferguson TS, Younger N, Tulloch-Reid MK, et al. Prevalence of metabolic syndrome in Jamaican adults and its relationship to income and education levels. West Indian Med J 2010; 59: 265-73.

7. $\mathrm{MOH} \& \mathrm{CDRC}$. The Barbados Health of the Nation Survey: Core Findings 2015. http://www.archive.healthycaribbean.org/newsletters/aug-2015/CDRC_HealthOfTheNationsurvey.pdf

8. PAHO. Trinidad and Tobago Pan American STEPS chronic non-communicable diseases risk factor survey. Final report 2012

9. Ballantyne CM, O'Keefe JH, AM G. Dyslipidemia and Athersclerosis Essentials. $4^{\text {th }}$ ed. Sudbury, Massachusetts, Jones and Bartlett 2009.

10. Anderson TJ, GregoireJ, Hegele RA, et al. 2012 update of Canadian Cardiovascular Society guidelines for the diagnosis and treatment of dyslipidemia for the prevention and treatment of cardiovascular disease in the adult. Can J Cardiol 2013; 29: 151-67.

11. Elisaf M, Tsimihodimos V. Secondary dyslipidemias. Open Cardiovasc Med J 2011; 5: 22-3.

12. Bosomworth NJ. Approach to identifying and managing atherogenic dyslipidemia. Can Fam Physician 2013; 59: 1169-80.

13. Varani SS. Non-HDL cholesterol as a metric of good quality of care opportunities and challenges. Texas Heart Instit J 2011; 38: 160-2.

14. Jones PH, Nair R, Thakker KM. Prevalence of dyslipidemia and lipid goal attainment in statin-treated subjects from 3 data sources: a retrospective analysis. J Am Heart Assoc 2012; 1: e001800.

15. Abubakar I, Tillmann T, Banerjee A. Global, regional, and national age-sex specific all-cause and cause-specific mortality for 240 causes of death, 1990-2013: a systematic analysis for the Global Burden of Disease Study 2013. Lancet 2015; 385: 117-71.

16. Harris MA, Ferguson TS, Figueroa JP. Improved hypertension control among primary care patients in Jamaica between 1995 and 2013. Global J Med Pub Health 2016; 5:

17. Parris ES, Lawrence DB, Mohn LA, Long LB. Adherence to statin therapy and LDL Cholesterol goal attainment by patients with diabetes and dyslipidemia. Diabetes Care 2005; 28: 595-9.

18. Colhoun HM, Betteridge DJ, Durrington PN, et al. Primary prevention of cardiovascular disease with atorvastatin in type 2 diabetes in the Collaborative Atorvastatin 
Diabetes Study (CARDS): multicentre randomised placebo-controlled trial. Lancet 2004; 364: 685-96.

19. Goodman G, Langer A, Bastien LA, et al. DYSIS Canadian Collaborators. Prevalence of dyslipidemia in statin-treated patients in Canada: results of the DYSlipidemia International Study (DYSIS). Canadian J Cardiol 2010; 26: 330-5.

20. Vian A, Kotseva K, Turner EL, et al. Dyslipidaemia and atherosclerotic vascular disease: DYSIS results in the UK. Br J Cardiol 2013; 29: S1-19.

21. Al Sifri SN, Almahmeed W, et al. Results of the Dyslipidemia International Study (DYSIS)-Middle East. Clinical perspective on the prevalence and characteristics of lipid abnormalities in the setting of chronic statin treatment. PLoS One 2014; 9: e843-50.

22. Gordon L, Ragoobirsingh D, Morrison EY, Choo-Kang E, McGrowder D, Martorell E. Lipid profile of type 2 diabetic and hypertensive patients in the Jamaican population. J Lab Physicians 2010; 2: 25-30.

23. Harris MA, Younger-Coleman N, Ferguson TS, Figueroa JP. Audit and feedback to improve the management of dyslipidemia in primary care in Jamaica: a randomized controlled trial. Global J Med Public Health 2016; 5: 1-9.

24. World Health Organization. Adherence to Long-Term Therapy: Evidence for Action. 2003.

25. Asnani M, Brown P, O'Connor D, Lewis T, Win S, Reid MA. A clinical audit of the quality of care of hypertension in general practice. West Indian Med J 2005; 54: 176-80.

26. Mitchell-Fearon K, Waldron NK, James K, Laws H, Holder-Nevins D, Eldemire-Shearer D. Hypertension and diabetes prevalence in older persons in Jamaica 2012. West Ind Med J 2014; 63: 416-23. 